\title{
Fluid balance and length of mechanical ventilation in children admitted to a single Pediatric Intensive Care Unit
}

\author{
Solange Vidal M.D. ${ }^{a}$,Augusto Pérez M.D. ${ }^{a}$ and Pablo Eulmesekian M.D. ${ }^{a}$
}

\begin{abstract}
Introduction. Associations between cumulative fluid balance and a prolonged duration of assisted mechanical ventilation have been described in adults. The aim of this study was to evaluate whether fluid balance in the first 48 hours of assisted mechanical ventilation initiation was associated with a prolonged duration of this process among children in the Pediatric Intensive Care Unit (PICU).

Methods. Retrospective cohort of patients in the PICU of Hospital Italiano de Buenos Aires, between 1/1/2010 and 6/30/2012. Balance was calculated in percentage of body weight; prolonged mechanical ventilation was defined as $\geq 7$ days, and confounders were registered. Univariate and multivariate analyses were performed.
\end{abstract}

Results. Two hundred and forty-nine patients were mechanically ventilated for over 48 hours; 163 were included in the study. Balance during the first 48 hours of mechanical ventilation was $5.7 \% \pm 5.86 ; 82$ patients $(50.3 \%)$ were on mechanical ventilation for more than 7 days. Age $<4$ years old (OR 3.21, 95\% CI 1.38-7.48, $p$ 0.007), respiratory disease (OR 4.94, 95\% CI $1.51-16.10, p$ 0.008), septic shock (OR 4.66, 95\% CI 1.10-19.65, $p$ 0.036), Pediatric Logistic Organ Dysfunction (PELOD) $>10$ (OR 2.44, 95\% CI1.23$4.85, p 0.011)$, and positive balance $>13 \%$ (OR $4.02,95 \%$ CI 1.08-15.02, $p$ 0.038) were associated with prolonged mechanical ventilation. The multivariate model resulted in an OR 2.58, 95\% CI: $1.17-5.58, p=0.018$ for PELOD $>10$, and an OR 3.7, 95\% CI: 0.91-14.94, $p=0.066$ for positive balance $>13 \%$.

Conclusions. Regarding prolonged mechanical ventilation, the multivariate model showed an independent association with organ dysfunction (PELOD > 10) and a trend towards an association with positive balance $>13 \%$.

Key words: fluid balance, mechanical ventilation, children, pediatric intensive care units.

http:/ /dx.doi.org/10.5546/aap.2016.eng.313

E-mail address:

Pablo Eulmesekian, M.D.

pablo.eulmesekian@

hospitalitaliano.org.ar

\section{Funding:}

None.

Conflict of interest:

None.

Received: 11-02-2015

Accepted: 03-11-2016 known as ventilator-associated lung injury, ${ }_{1}^{1}$ and were the reason for lungprotective ventilation strategies which resulted in a significant mortality reduction among patients with acute respiratory distress syndrome. ${ }^{2,3}$

Another approach to decreasing the risk of AMV-associated damage is to reduce exposure time. Different strategies have been studied to this end; and, in spite of having obtained non-conclusive results, in different intensive care units, sedation and ventilator weaning protocols with use of spontaneous breathing trials are in place. ${ }^{4-8}$ Another outcome measure related to the time of exposure to mechanical ventilation is fluid balance.

It was shown that fluid balance accumulation in the first 3-7 days was associated with more days on AMV among adult patients with acute pulmonary injury, ${ }^{9,10}$ and also to a higher mortality rate in patients with sepsis ${ }^{11,12}$ and with acute respiratory distress. ${ }^{13}$

In children, it was shown that the balance accumulated in the first 72 hours was associated with more days on AMV in patients with acute lung injury ${ }^{14,15}$ and in those in the cardiovascular postoperative period. ${ }^{16}$ A cumulative balance higher than 15\% of the body weight was demonstrated to be associated with impaired oxygenation and prolonged AMV. ${ }^{17}$

What this study is trying to demonstrate is if the association between fluid balance and prolonged AMV can be established with data corresponding to the first 48 hours of having started mechanical ventilation and is not limited to a subset of patients.

Therefore, the objective is to evaluate whether fluid balance in the 
first 48 hours of assisted mechanical ventilation initiation is associated with a prolonged duration of this process in the general population of patients hospitalized in the Pediatric Intensive Care Unit (PICU) of Hospital Italiano de Buenos Aires (HIBA). The secondary objective is to determine if there are other outcome measures -age, sex, decision to initiate AMV, Pediatric Index of Mortality 2 (PIM2), Pediatric Logistic Organ Dysfunction (PELOD), hypoxemic respiratory failure, and cardiovascular failure- associated with the same event.

\section{POPULATION AND METHODS}

\section{Setting}

The PICU at HIBA is a multidisciplinary 18bed unit which is part of a university general hospital. Seven hundred to seven hundred and fifty children are hospitalized annually; $25 \%-30 \%$ undergo AMV. In this unit, the type of conditions and situations managed are quite different, like post-transplant, complex post-operative period, cancer patients, and prevalent conditions.

\section{Design}

Retrospective cohort

\section{Study period}

From January $1^{\text {st }}, 2010$ to June 30 ${ }^{\text {th }}, 2012$.

\section{Population}

Inclusion criteria: on AMV for over 48 hours and age under 18 years old.

Exclusion criteria: patients who had received renal function replacement therapy, burn patients, patients on home-AMV, patients on AMV before being admitted to the PICU, infants under 30 days of life, and patients whose medical records had incomplete information.

\section{Data collection instruments}

As data source, the electronic medical record and an administrative database were used to register hospital length of stay and AMV duration.

A form especially designed for this study was used to collect data of included patients.

\section{Outcome measure operationalization}

Fluid balance

It is calculated by the difference between the total amount of fluid administered and the sum of all the losses experienced during the first 48 hours of AMV: It is expressed in percentage of the patient's body weight as per the following formula: ${ }^{17,18}$ (fluid input - fluid output)/body weight x 100 .

To calculate fluid balance, the patient's weight is measured upon admission, and insensible losses are disregarded because in all ventilated patients active humidification and heating systems are used. ${ }^{17,18}$

\section{Prolonged mechanical ventilation}

In the bibliography, different terms are used to define prolonged mechanical ventilation (PMV): $\geq 48$ hours,$^{19} \geq 96$ hours, ${ }^{20} \geq 7$ days, ${ }^{21,22}$ and $\geq 21$ days. ${ }^{23}$

In this study, it was considered that PMV was the AMV period equal to or longer than 7 days. ${ }^{21,22}$

\section{Fluids administered}

The fluid volume calculated by the Holliday formula is called $100 \%$ and, in reference to this value, it reports the volume of administered fluid. ${ }^{24}$

\section{Decision to initiate assisted mechanical ventilation}

Reported as diagnostic categories: neurological, cardiovascular, respiratory, liver conditions, sepsis, and others.

\section{Pediatric Index of Mortality 2 (PIM2)}

Score that estimates mortality risk in the intensive care setting from data collected at the time of PICU admission, validated in our setting. ${ }^{26}$

\section{Pediatric Logistic Organ Dysfunction (PELOD)}

This score assigns points to each organ that fails according to severity, and then is summed up in a score corresponding to the sum of individual scores..$^{27}$ It was validated in Europe and Canada, ${ }^{28}$ and in our setting. ${ }^{29}$

\section{Hypoxemic respiratory failure}

Defined as $\mathrm{PaO}_{2} / \mathrm{FIO}_{2}<200$ in absence of cyanotic heart disease or left ventricular dysfunction. ${ }^{30-33}$

\section{Cardiovascular failure}

Defined as arterial hypotension $\left(<5^{\text {th }}\right.$ percentile for the age) or the need to use vasoactive drugs (dopamine, epinephrine, norepinephrine at any dose)..$^{30,31}$

\section{Other outcome measures}

Age, sex, weight, baseline disease, AMV as part of the post-operative management, $\mathrm{PaO}_{2} /$ $\mathrm{FIO}_{2}$, days of hospitalization, and mortality in the PICU. 


\section{Statistical analysis}

Outcome measure characteristics and distribution were analyzed, and means and standard deviations, medians, inter-quartile ranges, or proportions were used.

A univariate analysis between each independent outcome measure and the dependent AMV outcome measure was conducted. Dichotomous outcome measures were introduced in the same way; categorical outcome measures were transformed into dummies, and continuous outcome measures were transformed into dichotomous ones. To this end, the frequency of PMV was investigated in its quintiles, cut-off points in the ROC curve were analyzed and, in some outcome measures (PIM2, PELOD), it was clinically defined.

Outcome measures with a $p<0.20$ were manually introduced in the multivariate model. The only outcome measures that remained were those that improved predictive ability, were significantly associated with the event, or were considered clinically relevant. The relationship between independent outcome measures and the number of events was 1 to 10 .

In the final model, calibration and discrimination were evaluated. The former, by the Hosmer-Lemeshow in deciles of risk, and the latter, by the area under the ROC curve. Overall calibration with a $p>0.05$ and a discrimination with an area under the ROC curve $>0.7$ were considered adequate. ${ }^{34}$

The statistical analysis was performed with the Stata 9 software, Statacorp, Texas.

\section{Ethical considerations}

The study was approved by the Research Protocol Evaluation Committee of HIBA. Taking into account the characteristics of its design, it was defined that it was not necessary to obtain the informed consent. Data were managed in agreement with the Protection of Personal Information Act (National Law N ${ }^{\circ}$ 25326).

\section{RESULTS}

During the study period, 1655 patients were admitted to the PICU; 249 remained on AMV for over 48 hours and 163 were included in the study (Figure 1).

The characteristics of the population are summarized in Table 1. The median (25-75) age of this population was 1.2 years old (0.4-3.3); they received in the first 48 hours of AMV initiation, a mean $( \pm \mathrm{SD})$ of $123.2 \%( \pm 40.11)$ of fluids; and had a balance mean $( \pm \mathrm{SD})$ of $5.7 \%( \pm 5.86)$ of the body weight. As far as AMV, 50.3\% of patients were connected to the ventilator for more than 7 days.

The univariate analysis showed that the age younger than 4 years old (OR 3.21, 95\% CI: 1.38-7.48), respiratory disease (OR 4.94, 95\% CI: 1.51-16.10), septic shock (OR 4.66, 95\% CI: 1.1019.65), PELOD > 10 ( OR 2.44, 95\% CI: 1.23- 4.85), and positive balance $>13 \%$ of the body weight (OR 4.02, 95\% CI: 1.08-15.02) were associated with PMV (Table 2).

The multivariate model indicated that PELOD > 10 (OR 2.58, 95\% CI: 1.17-5.58) remained independently associated with the event and the outcome measures of interest; positive balance $>13 \%$ showed a trend towards the association with PMV (OR 3.7, 95\% CI: 0.91-14.94) (Table 3).

The model adjustment was adequate. The Hosmer-Lemeshow test resulted in a $p>0.05$ $(p=0.3648)$ and the number of events observed and estimated by the model in each decile of risk is summarized in Table 4.

The model discrimination estimated by an area under the ROC curve was 0.73 (95\% CI: 0.65-0.80).

\section{DISCUSSION}

The study shows, through the univariate analysis, that in a general population of patients hospitalized in the PICU of HIBA, in the first 48 hours of AMV initiation, five outcome measures are statistically significantly associated with PMV:

FIGURE 1. Flow of patients

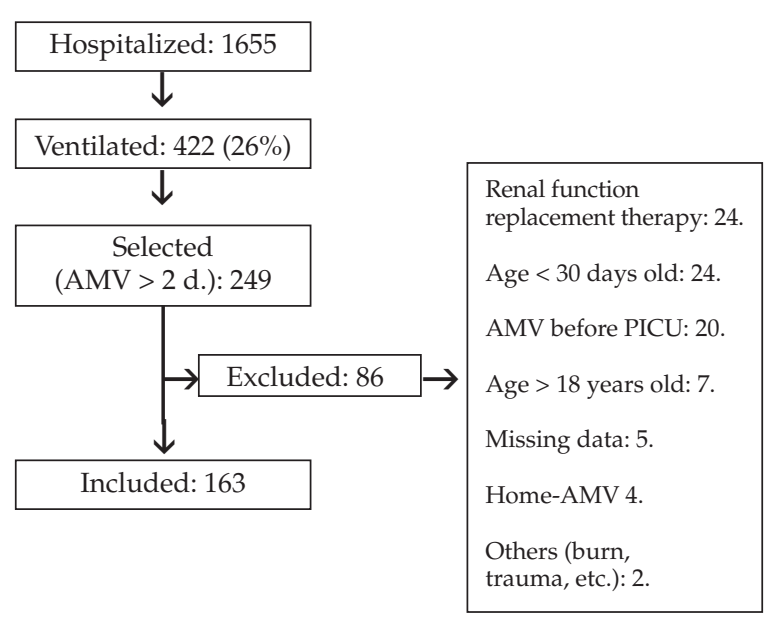

AMV: assisted mechanical ventilation. PICU: Pediatric Intensive Care Unit. 
age $<4$ years old, respiratory disease and sepsis as a decision to initiate AMV, organ dysfunction defined as PELOD $>10$, and positive balance $>13 \%$ of the body weight.

The multivariate analysis reflects that only one of these outcome measures is independently associated with PMV, PELOD $>10$. The outcome measure of interest, positive balance $>13 \%$, remains close to reaching statistical significance, with an $\mathrm{OR}=3.7$, a $p=0.066$, and a broad 95\% CI (0.91-14.94).

These results are interpreted as a trend that fluid balance in the first 48 hours of AMV initiation is associated with more days of mechanical ventilation. The $p$ value and the broad $\mathrm{CI}$ might indicate that statistical significance is not reached given that there is a small number of patients with a positive balance greater than $13 \%$ of the body weight $(n=16)$. The cut-off point of the balance outcome measure to treat it dichotomically comes from the analysis of the frequency of PMV in the quintiles of the outcome measure and the analysis of the ROC curve.

TABLE 1. Characteristics of the studied population: $n=163$

\begin{tabular}{|c|c|}
\hline Outcome measure & Summary metric \\
\hline Age in years, median (25-75) & $1.2(0.4-3.3)$ \\
\hline Weight in kg, median (25-75) & $8.8(5.5-13)$ \\
\hline Male sex, $\mathrm{n}(\%)$ & $86(52.7)$ \\
\hline Underlying disease, $\mathrm{n}(\%)$ & $146(89.6)$ \\
\hline \multicolumn{2}{|l|}{ Decision to initiate AMV } \\
\hline Respiratory, n (\%) & $47(28.83)$ \\
\hline Cardiovascular, n (\%) & $45(27.61)$ \\
\hline Neurological, n (\%) & $19(11.66)$ \\
\hline Liver, n (\%) & $19(11.66)$ \\
\hline Septic shock, n (\%) & $16(9.82)$ \\
\hline Others, $\mathrm{n}(\%)$ & $17(10.43)$ \\
\hline PIM2, mean $( \pm S D)$ & $6.74( \pm 13.12)$ \\
\hline PELOD, median (25-75) & $12(2-12)$ \\
\hline Post-operative AMV, n (\%) & $70(42.9)$ \\
\hline $\mathrm{PaO}_{2} / \mathrm{FIO}_{2}$, mean $( \pm \mathrm{SD})$ & $178.6( \pm 94.85)$ \\
\hline Hypoxemic respiratory failure, $\mathrm{n}(\%)$ & $103(63.1)$ \\
\hline Cardiovascular failure, $\mathrm{n}(\%)$ & $104(63.8)$ \\
\hline Days of AMV, median (25-75) & $8(5-16)$ \\
\hline Hospitalization days, median (25-75) & $18(11-31)$ \\
\hline \multicolumn{2}{|l|}{ Fluid during the first 48 hours with AMV } \\
\hline \multicolumn{2}{|c|}{ Balance during the first 48 hours with AMV } \\
\hline in $\%$ of weight, mean $( \pm S D)$ & $5.7( \pm 5.86)$ \\
\hline Prolonged AMV, n (\%) & $82(50.3)$ \\
\hline Mortality, n (\%) & $16(9.8)$ \\
\hline
\end{tabular}

AMV: assisted mechanical ventilation; BNs: baseline needs; PIM2: pediatric index of mortality 2;

PELOD: pediatric logistic organ dysfunction score;

SD: standard deviation.
Arikan studied the association between the balance and the duration of mechanical ventilation in a retrospective cohort of 80 pediatric patients who were on AMV for over 24 hours. In this population, it was shown that those who had a positive balance greater than $15 \%$ of the body weight were on the ventilator for a longer time. This threshold is similar to the cut-off point chosen in this study to dichotomically treat the balance outcome measure. ${ }^{17}$

TABLE 2. Univariate analysis: Outcome measure dependent on prolonged mechanical ventilation ( $n=163$; events: 82$)$

\begin{tabular}{lccc}
\hline Outcome measure & OR & $\boldsymbol{P}$ & $\mathbf{9 5 \%} \mathbf{C I}$ \\
\hline Age $<4$ years old & 3.21 & 0.007 & $1.38-7.48$ \\
Male sex & 1.18 & 0.586 & $0.64-2.19$ \\
Decision to initiate AMV & & & \\
$\quad$ Cardiovascular & 2.92 & 0.074 & $0.90-9.49$ \\
$\quad$ Respiratory & 4.94 & 0.008 & $1.51-16.10$ \\
$\quad$ Liver & 2.03 & 0.308 & $0.51-7.99$ \\
$\quad$ Others & 1.52 & 0.560 & $0.36-6.35$ \\
$\quad$ Septic shock & 4.66 & 0.036 & $1.10-19.65$ \\
PIM2 > 5 & 0.82 & 0.573 & $0.42-1.61$ \\
PELOD $>10$ & 2.44 & 0.011 & $1.23-4.85$ \\
Post-operative AMV & 0.59 & 0.100 & $0.31-1.10$ \\
Hypoxemic respiratory failure & 1.01 & 0.952 & $0.53-1.92$ \\
PaO FIO $_{2}$ & 0.99 & 0.175 & $0.99-1.00$ \\
Cardiovascular failure & 1.48 & 0.231 & $0.77-2.81$ \\
Fluids $>160$ BNs & 1.44 & 0.351 & $0.66-3.12$ \\
Positive balance $>$ 13\% weight & 4.02 & 0.038 & $1.08-15.02$ \\
& & & \\
\hline
\end{tabular}

AMV: assisted mechanical ventilation; BNs: baseline needs; PMV: prolonged mechanical ventilation; OR: odds ratio; CI: confidence interval; PIM2: pediatric index of mortality 2; PELOD: pediatric logistic organ dysfunction score.

TABLE 3. Multivariate analysis: Outcome measure dependent on prolonged mechanical ventilation ( $n=163$; events: 82$)$

\begin{tabular}{lccc}
\hline Outcome measure & OR & $\boldsymbol{P}$ & $\mathbf{9 5 \%} \mathbf{C I}$ \\
\hline Pos. bal. $>13 \%$ & 3.70 & 0.066 & $0.91-14.94$ \\
Age $<4$ years old & 2.30 & 0.088 & $0.88-6.04$ \\
Decision to initiate AMV & & & \\
$\quad$ Cardiovascular & 1.39 & 0.615 & $0.37-5.18$ \\
$\quad$ Respiratory & 3.03 & 0.097 & $0.81-11.23$ \\
$\quad$ Liver & 2.01 & 0.380 & $0.42-9.46$ \\
$\quad$ Others & 0.92 & 0.918 & $0.19-4.42$ \\
$\quad$ Septic shock & 3.44 & 0.116 & $0.73-16.10$ \\
PIM2 $>5$ & 0.68 & 0.365 & $0.30-1.55$ \\
PELOD $>10$ & 2.58 & 0.018 & $1.17-5.68$ \\
\hline
\end{tabular}

Pos. bal.: positive balance;

AMV: assisted mechanical ventilation; OR: odds ratio; CI: confidence interval; PIM2: pediatric index of mortality 2; PELOD: pediatric logistic organ dysfunction score. 
Other pediatric studies reported associations between balance and AMV duration. Cumulative fluid balance at 72 hours from acute lung injury diagnosis was associated with a higher mortality in the study by Flori, ${ }^{14}$ and to a lower number of ventilator-free days. ${ }^{15}$ The current study is consistent with these reports. The univariate analysis shows that there is an association between balance and PMV, and unlike the former studies, it extends to the first 48 hours of AMV initiation and does not limit it to the population of patients with acute lung injury.

However, the multivariate model showed that only the organ dysfunction outcome measure (PELOD > 10) was independently associated with PMV, and that the outcome measure under study only showed a trend towards the association with the event.

Two explanations are proposed for these findings.

The first one is, that there truly is an association between balance and PMV, regardless of the other outcome measures included in the model, but this does not reach statistical significance, given the small number of patients with a positive balance $>13 \%(n=16)$. In line with this trend of thought, it would be reasonable to consider that, by controlling fluid balance with the administration of diuretics or hemofiltration techniques, the time of exposure to AMV could be diminished.

The second explanation is that there is not a true association between balance and PMV; the single outcome measure independently associated with PMV is organ dysfunction (PELOD $>10$ ). The trend observed between fluid balance and

TABLE 4. Events observed and estimated in deciles of risk (Hosmer-Lemeshow)

\begin{tabular}{lcccccc}
\hline $\begin{array}{c}\text { Decile } \\
\begin{array}{c}\text { Estimated } \\
p \text { model }\end{array}\end{array}$ & $\begin{array}{c}\text { Observed } \\
\text { PMV }\end{array}$ & $\begin{array}{c}\text { Estimated } \\
\text { PMV }\end{array}$ & $\begin{array}{c}\text { Observed } \\
\text { No PMV }\end{array}$ & $\begin{array}{c}\text { Estimated } \\
\text { No PMV }\end{array}$ & Total \\
\hline 1 & 0.2375 & 2 & 3 & 15 & 14 & 17 \\
2 & 0.3171 & 7 & 4.9 & 10 & 12.1 & 17 \\
3 & 0.3748 & 5 & 5.1 & 10 & 9.9 & 15 \\
4 & 0.4669 & 8 & 7.5 & 9 & 9.5 & 17 \\
5 & 0.5384 & 5 & 8.6 & 12 & 8.4 & 17 \\
6 & 0.5506 & 17 & 17 & 14 & 14 & 31 \\
7 & 0.6322 & 0 & 0.6 & 1 & 0.4 & 1 \\
9 & 0.7264 & 25 & 22.3 & 7 & 9.7 & 32 \\
10 & 0.9076 & 13 & 12.9 & 3 & 3.1 & 16 \\
\hline
\end{tabular}

PMV: prolonged mechanical ventilation.
PMV might correspond to a certain degree of colinearity between balance and PELOD. Thus, the balance outcome measure could be considered as a surrogate endpoint of organ dysfunction and disease severity. This reasoning has biological plausibility since those who are more severely ill have a greater possibility of being on AMV, and tend to receive a larger amount of fluid and have more difficulties to remove it.

The best approach to deal with this uncertainty would be to conduct a randomized clinical trial comparing different fluid management strategies in different groups of ventilated pediatric patients, similar as far as AMV management and the severity of their clinical condition.

This study has certain limitations. Its retrospective character does not allow to ensure that fluid administration and AMV strategies used in the studied population were similar; the fact that this strategy has been implemented in only one PICU determines that findings cannot be extrapolated to other units; the presence of potential non-studied or unknown confounders that would eventually modify the power of association between the study outcome measure and the event; the small number of patients with positive balance $>13 \%$ of the body weight $(n=16)$, which would account for a value close to statistical significance obtained in the multivariate model; and finally, the overlooking of insensible losses when calculating balance given that they are considered as minimal losses when patients are in a setting with controlled temperature and are ventilated with systems of active humidification.

\section{CONCLUSION}

In the first 48 hours of AMV initiation, in a general population of patients hospitalized in the PICU of HIBA, the multivariate model showed a trend toward the association between the outcome measure in study, that is positive balance $>13 \%$ and PMV, organ dysfunction evaluated by PELOD score, and staying on the ventilator for over 7 days.

\section{REFERENCES}

1. Slutsky AS, Ranieri VM. Ventilator-induced lung injury. $N$ Engl J Med 2013;369(22):2126-36.

2. The Acute Respiratory Distress Syndrome Network. Ventilation with lower tidal volumes as compared with traditional tidal volumes for acute lung injury and the acute respiratory distress syndrome. $N$ Engl J Med 2000;342(18):1301-8.

3. Amato MB, Barbas CS, Medeiros DM, Magaldi RB, et al. Effect of a protective-ventilation strategy on mortality 
in the acute respiratory distress syndrome. $N$ Engl J Med 1998;338(6):347-54.

4. Gupta K, Gupta VK, Jayashree M, Singhi S. Randomized controlled trial of interrupted versus continuous sedative infusions in ventilated children. Pediatr Crit Care Med 2012;13(2):131-5.

5. Kress JP, Pohlman AS, O'Connor MF, Hall JB. Daily interruption of sedative infusions in critically ill patients undergoing mechanical ventilation. $\mathrm{N}$ Engl J Med 2000;342(20):1471-7.

6. Foronda FK, Troster EJ, Farias JA, Barbas CS, et al. The impact of daily evaluation and spontaneous breathing teston theduration of pediatricmechanical ventilation: a randomized controlled trial. Crit Care Med 2011;39(11):2526-33.

7. Ferguson LP, Walsh BK, Munhall D, Arnold JH. A spontaneous breathing trial with pressure support overestimates readiness for extubation in children. Pediatr Crit Care Med 2011;12(6):e330-5.

8. Blackwood B, Murray M, Chisakuta A, Cardwell CR, et al. Protocolized versus non-protocolized weaning for reducing the duration of invasive mechanical ventilation in critically ill paediatric patients. Cochrane Database Syst Rev 2013;7:CD009082.

9. Wiedemann HP, Wheeler AP, Bernard GR, Thompson BT, et al. Comparison of twochechu fluid-management strategies in acute lung injury. N Engl J Med 2006;354(24):2564-75.

10. Stewart RM, Park PK, Hunt JP, McIntyre RC Jr, et al. Less is more: improved outcomes in surgical patients with conservative fluid administration and central venous catheter monitoring. J Am Coll Surg 2009;208(5):725-35.

11. Vincent JL, Sakr Y, Sprung CL, Ranieri VM, et al. Sepsis in European intensive care units: results of the SOAP study. Crit Care Med 2006;34(2):344-53.

12. Boyd JH, Forbes J, Nakada TA, Walley KR, et al. Fluid resuscitation in septic shock: a positive fluid balance and elevated central venous pressure are associated with increased mortality. Crit Care Med 2011;39(2):259-65.

13. Sakr Y, Vincent JL, Reinhart K, Groeneveld J, et al. High tidal volume and positive fluid balance are associated with worse outcome in acute lung injury. Chest 2005;128(5):3098-108.

14. FloriHR, Church G, Liu KD, Gildengorin, etal. Positivefluid balance is associated with higher mortality and prolonged mechanical ventilation in pediatric patients with acutelung injury. Crit Care Res Pract 2011;2011:854142.

15. Valentine SL, Sapru A, Higgerson RA, Spinella PC, et al. Fluid balance in critically ill children with acutelung injury. Crit Care Med 2012;40(10):2883-9.

16. Seguin J, Albright B, Vertullo L, Lai P, et al. Extent, risk factors, and outcome of fluid overload alter pediatric heart surgery. Crit Care Med 2014;42(12):2591-9.

17. Arikan AA, Zappitelli M, Goldstein SL, Naipaul A, et al. Fluid overload is associated with impaired oxygenation and morbidity in critically ill children. Pediatr Crit Care Med 2012;13(3):253-8.

18. GoldsteinSL,CurrierH,GrafJM,CosioCC, etal. Outcomein children receiving continuous venovenous hemofiltration. Pediatrics 2001;107(6):1309-12.

19. Chelluri L, Im KA, Belle SH, Schulz R, et al. Long-term mortality and quality of life after prolonged mechanical ventilation. Crit Care Med 2004;32(1):61-9.

20. Zilberberg MD, Kramer AA, Higgins TL, Shorr AF. Prolonged acute mechanical ventilation: implications for hospital benchmarking. Chest 2009;135(5):1157-62.

21. Polito A, Patorno E, CostelloJM, SalvinJW, etal.Perioperative factors associated with prolonged mechanical ventilation after complex congenital heart surgery. Pediatr Crit Care Med 2011;12(3):e122-6.

22. CoxCE,CarsonSS, GovertJA, Chelluri L, etal. An economic evaluation of prolonged mechanical ventilation. Crit Care Med 2007;35(8):1918-27.

23. Traiber C, Piva JP, Fritsher CC, Garcia PC, et al. Profile and consequences of children requiring prolonged mechanical ventilation in three Brazilian pediatric intensive care units. Pediatr Crit Care Med 2009;10(3):375-80.

24. Holliday MA, Segar WE. The maintenance need for water in parenteral fluid therapy. Pediatrics 1957;19(5):823-32.

25. Slater A, Shann F, Pearson G. PIM2: a revised version of the Paediatric Index of Mortality. Intensive Care Med 2003;29(2):278-85.

26. Eulmesekian PG, Pérez A, Minces PG, Ferrero H. Validation of Pediatric Index of Mortality 2 (PIM2) in a single pediatric intensive care unit of Argentina. Pediatr Crit Care Med 2007;8(1):54-7.

27. Leteurtre S, Martinot A, Duhamel A, Gauvin F, et al. Development of a pediatric multipleorgan dysfunction score : use of two strategies. Med Decis Making 1999;19(4):399-410.

28. Leteurtre S, Martinot A, Duhamel A, Proulx F, et al. Validation of the paediatric logistic organ dysfunction (PELOD) score: prospective, observational, multicenter study. Lancet 2003;362(9379):192-7.

29. Garcia PC, Eulmesekian P, Branco RG, Perez A, et al. External validation of the paediatric logistic organ dysfunction score. Intensive Care Med 2010;36(1):116-22.

30. Goldstein B, Giroir B, Randolph A. International pediatric sepsis consensus conference: definitions for sepsis and organ dysfunction in pediatrics. Pediatr Crit Care Med 2005;6(1):2-8.

31. Typpo KV, Petersen NJ, Hallman DM, Markovitz BP, et al. Day 1 multiple organ dysfunction syndrome is associated with poor functional outcome and mortality in the pediatric intensive care unit. Pediatr Crit Care Med 2009;10(5):562-70.

32. Ghuman AK, Newth CI, Khemani RG. The association between the end tidal alveolar dead space fraction and mortality in pediatric acute hypoxemic respiratory failure. Pediatr Crit Care Med 2012;13(1):11-5.

33. Trachsel D, McCrindle BW, Nakagawa S, Bohn D. Oxygenation index predicts outcome in children with acute hypoxemic respiratory failure. Am J Respir Crit Care Med 2005;172(2):206-11.

34. Hosmer DW, Lemeshow S, Sturdivant RX. Applied logistic regression. 3rd ed. New Jersey: Wiley; 2013. 